\title{
Correction to: A Global Assessment of Access to and Use of Medical Information: The State of Evidence-Based Surgery
}

\section{Lacey N. LaGrone ${ }^{1} \cdot$ Amy K. Fuhs $^{2} \cdot$ Eduardo Huaman Egoavil $^{3}$ •}

Lorrie A. Langdale $^{1}$ - Phupit Fuangworawong ${ }^{1} \cdot$ Jose Luis Hamasaki $^{4}$. Adam Gyedu ${ }^{5} \cdot$ Charles N. Mock $^{1}$

Published online: 13 October 2017

(C) Société Internationale de Chirurgie 2017

\section{Correction to: World J Surg}

DOI 10.1007/s00268-017-4175-4

In the original article some funding information was inadvertently omitted. The complete funding information is as follows:
National Institutes of Health Research Training Grants \#R25 TW009345 and \#D43 TW007267.
The online version of the original article can be found under doi:10.1007/s00268-017-4175-4.

Lacey N. LaGrone

lagronel@uw.edu

Amy K. Fuhs

akfuhs@iupui.edu

Eduardo Huaman Egoavil

edhu562000@gmail.com

Lorrie A. Langdale

lorrie@uw.edu

Phupit Fuangworawong

dr_toon23@hotmail.com

Jose Luis Hamasaki

joseluishamasaki@yahoo.com

Adam Gyedu

drgyedu@gmail.com
Charles N. Mock

cmock@uw.edu

1 Harborview Injury Prevention and Research Center, University of Washington, Campus Box \#356410, Seattle, WA 98104, USA

2 Indiana University School of Medicine, Indianapolis, IN, USA

3 Hospital Nacional Guillermo Almenara, Lima, Peru

4 Hospital Central de la Policía Nacional del Perú, Lima, Peru

5 Kwame Nkrumah University of Science and Technology, Kumasi, Ghana 